\title{
Association of the G134A and G184C Polymorphisms in the CYP1A1 Gene with Lung Cancer Incidence
}

\author{
Doug-Young Ryu ${ }^{1}$, Mingai Huang ${ }^{2}$, Changbo Park', Soo Im Chang', Ruth Im², Seong-Jin Choi $^{2}$, \\ Na-Young Kim ${ }^{2}$, In Won Park', Byoung Whui Choi ${ }^{2}$, Jae Yeol Kim², Jong Wook Shin', \\ Jae Chul Choi ${ }^{2}$, Byung-Sun Choi ${ }^{2}$ and Jung-Duck Park ${ }^{2}$ \\ ${ }^{1}$ College of Veterinary Medicine, Seoul National University, Seoul 151-742 \\ ${ }^{2}$ College of Medicine, Chung-Ang University, Seoul 156-756, Korea
}

Received February 1, 2008; Revised March 6, 2008; Accepted March 7, 2008

\begin{abstract}
The G184C and G134A single nucleotide polymorphisms (SNPs) of the CYP1A1 gene result in Ala62Pro and Gly45Asp substitutions, respectively. Here, we tested whether these SNPs are associated with an alteration in lung cancer incidence. We examined 80 Korean subjects with lung cancer and 240 age- and sex-matched controls. For each subject, the CYP1A1 gene was PCR amplified and sequenced. We observed that the odds ratio (OR) for lung cancer was 3.37 higher in subjects with the G184C polymorphism than in controls (95\% confidence interval $(\mathrm{Cl}), 0.89 \sim 12.73, P=0.07$ ). In contrast, the OR for lung cancer was 1.23 in subjects with the G134A polymorphism compared to controls $(95 \% \mathrm{Cl}, 0.68 \sim 2.20, P=0.49)$. The $\mathrm{G} 184 \mathrm{C}$ polymorphism exacerbated the effects of smoking on lung cancer development. Gene-smoking interaction analyses revealed that past or present smokers with the $\mathrm{G} 184 \mathrm{C}$ polymorphism had a higher incidence of lung cancer (OR, 24.72; $95 \% \mathrm{Cl}$, 4.48 136.31; $P<0.01$ ) than control smokers (OR, 6.65; 95\% Cl, 2.72 16.28; $P<0.01$ ). However, there was only a slight difference in the ORs for lung cancer between control smokers and smokers with the G134A polymorphism. These findings suggest that the $\mathrm{G} 184 \mathrm{C}$ polymorphism, but not the G134A polymorphism, is associated with an increased risk of lung cancer.
\end{abstract}

Key words: CYP1A1, Single nucleotide polymorphism, G134A, G184C, Gly45Asp, Ala62Pro, Lung cancer.

\section{INTRODUCTION}

The CYP1A1 enzyme is a member of the human cytochrome P-450 family. It acts by metabolizing xenobiotics including the tobacco carcinogen benzo[a]pyrene and other polycyclic aromatic hydrocarbons to mutagenic epoxide and diols [e.g. benzo[a]pyrene-diol-epoxide] (McManus et al., 1990; Bartsch et al., 2000). To date, more than 17 nucleotide polymorphisms including at positions such as - 3229, - 3219, 134, 184, 233, 518, 1413 (SNP ID: rs4987133), 1636, 2414, 2453, 2455, $2461,2500,2515,2546,3205$, and 3801 and a frameshift mutation (due to a single base insertion between 2346 and 2347) in the CYP1A1 gene have been

Correspondence to: Jung-Duck Park, College of Medicine, Chung-Ang University, Seoul 156-756, Korea

E-mail: jdpark@cau.ac.kr

Abbreviations: CYP, cytochrome P-450; $\mathrm{Cl}$, confidence interval; OR, odds ratio; PCR, polymerase chain reaction; SNP, single nucleotide polymorphism; WT, wild-type. reported (Spurr et al., 1987; Hayashi et al., 1991; Crofts et al., 1993; Cascorbi et al., 1996; Smart et al., 2000; Chevalier et al., 2001; Saito et al., 2002; Park et al., 2004, Solus et al., 2004).

Because of its metabolic role in the production of active carcinogens, it is not surprising that CYP1A1 polymorphisms have been linked with lung cancer. Two of the best understood polymorphisms include a transition of T3801C in the $3^{\prime}$ non-coding region, which results in the introduction of an Mspl restriction site and a transition of $\mathrm{A} 2455 \mathrm{G}$, which results in an lle to Val change. These SNP mutations have been associated with an increased risk of lung cancer in various ethnic groups (Song et al., 2001; Sugimura et al., 1998; Hung et al., 2003; Vineis et al., 2003).

The G184C and G134A polymorphisms of CYP1A1 result in Ala62Pro and Gly45Asp substitutions, respectively, and were first identified in Korean and Japanese populations, respectively (Chevalier et al., 2001; Saito et al., 2002). However, the functional role of these poly- 
morphisms in cancer susceptibility has not been addressed. In the present study, we have tested the effects of these two polymorphisms and their relationships with smoking in terms of the risk of lung cancer incidence.

\section{MATERIALS AND METHODS}

Study subjects. Our study included 80 lung cancer patients between 30 and 91 years of age that were admitted to Chung-Ang University Hospital (Seoul, Korea) between 2005 and 2007. For each patient, three controls were randomly selected by matching sex and ages, were \pm 3 years of age of the patients, and had not been diagnosed with lung cancer. All subjects gave written informed consent to participate in this study. This study was approved by the Ethics Committee for the Protection of Persons and Animals in Biochemical Research at the Institute of Medical Science, ChungAng University (Seoul, Korea).

Genotyping analysis. Genomic DNA extracted from the blood from each participating individual was amplified by polymerase chain reaction (PCR). Primers for the PCR were designed to produce DNA fragments encompassing Gly45 and Ala62 (Accession \#X02612). The primer sequences were 5'-CCA ATC TGA CGG CTT GAC TT-3' and 5'-CCC ATG CAG TTC CTC TTA CC-3'. PCR was performed for 35 cycles at $94^{\circ} \mathrm{C}$ for $1 \mathrm{~min}, 59^{\circ} \mathrm{C}$ for $1 \mathrm{~min}$, and $72^{\circ} \mathrm{C}$ for $1 \mathrm{~min}$. After amplifications, PCR products were analyzed by DNA sequencing using a 5'-CCG GCC CTT GAA ATC ATC-3' primer.

Linkage analysis between the G184C and G134A polymorphisms was performed for the subjects who had both polymorphisms. The PCR products were cloned into the TA vector PGEM-T Easy system (Promega, Madison, $\mathrm{WI}$ ), and the individual clones were sequenced using the T7 primer.

Statistical analysis. The odds ratios (ORs) and 95\% confidence intervals (Cls) were analyzed in a conditional logistic regression model using the PhReg procedure in SAS version 10.1 (SAS Institute, Cary, NC).

\section{RESULTS AND DISCUSSION}

The defining characteristics of the study subjects are shown in Table 1. A total of 248 males and 72 females participated in this study. The average age of the lung cancer patients and controls were $66.3 \pm 10.7$ and $65.6 \pm$

Table 1. Demographic characteristics of study subjects

\begin{tabular}{lcccc}
\hline \hline Characteristics & Number of patients & Number of controls & OR $(95 \% \mathrm{Cl})$ & $\mathrm{p}$ value \\
\hline Subjects & 80 & 240 & & \\
Gender & 62 & 186 & \\
$\quad$ Male & 18 & 54 & \\
$\quad$ Female & $66.3 \pm 10.7$ & $65.6 \pm 9.9$ & & \\
Age (mean in years \pm S.D.) & 17 & 110 & 1.00 & $<0.01$ \\
Smoking & 63 & 130 & $6.93(2.83 \sim 16.98)$ \\
$\quad$ Non-smoker & & & \\
$\quad$ Smoker (past or present) & & & & \\
\hline
\end{tabular}

Table 2. Association between lung cancer incidence and the $\mathrm{G} 134 \mathrm{~A}$ and $\mathrm{G} 184 \mathrm{C}$ polymorphisms in the CYP1A1 gene

\begin{tabular}{|c|c|c|c|c|}
\hline Subjects & Number of patients & Number of controls & OR $(95 \% \mathrm{Cl})$ & $\bar{p}$ p value \\
\hline Without G134A & 56 & 177 & 1.00 & \\
\hline G184C/WT & 3 & 2 & & \\
\hline WT/WT & 53 & 175 & & \\
\hline With G134A & 24 & 63 & $1.23(0.68 \sim 2.20)$ & 0.49 \\
\hline G134A/G134A & 1 & 3 & & \\
\hline G134A/WT & 21 & 57 & & \\
\hline G134A/G184C & 2 & 3 & & \\
\hline Without G184C & 75 & 235 & 1.00 & \\
\hline G134A/G134A & 1 & 3 & & \\
\hline G134A/WT & 21 & 57 & & \\
\hline WT/WT & 53 & 175 & & \\
\hline With G184C & 5 & 5 & $3.37(0.89 \sim 12.73)$ & 0.07 \\
\hline G134A/G184C & 2 & 3 & & \\
\hline G184C/WT & 3 & 2 & & \\
\hline
\end{tabular}


Table 3. Effects of either the G134A or G184C polymorphism of CYP1A1 and smoking on the risk of developing lung cancer

\begin{tabular}{|c|c|c|c|c|c|}
\hline Subject & Smoking & Number of patients & Number of controls & OR $(95 \% \mathrm{Cl})$ & $p$ value \\
\hline Without G134A & No & 14 & 87 & 1.00 & \\
\hline With G134A & No & 3 & 23 & $0.92(0.24 \sim 3.47)$ & 0.90 \\
\hline Without G134A & Yes & 42 & 90 & $6.48(2.48 \sim 16.92)$ & $<0.01$ \\
\hline With G134A & Yes & 21 & 40 & 7.91 (2.67 23.43) & $<0.01$ \\
\hline Without G184C & No & 17 & 109 & 1.00 & \\
\hline With G184C & No & 0 & 1 & - & - \\
\hline Without G184C & Yes & 58 & 126 & $6.65(2.72 \sim 16.28)$ & $<0.01$ \\
\hline With G184C & Yes & 5 & 4 & $24.72(4.48 \sim 136.31)$ & $<0.01$ \\
\hline
\end{tabular}

Subjects with and without each polymorphism were separated according to smoking status.

9.9 , respectively. Smoking was associated with a $6.93-$ fold increased risk of lung cancer $(95 \% \mathrm{Cl}, 2.83 \sim 16.98$; $P<0.01)$.

The distribution of the CYP1A1 polymorphisms among all participants is shown in Table 2. Allelic frequencies of G134A and G184C polymorphisms were $14.2 \%$ (91 alleles) and $1.6 \%$ (10 alleles) among the 320 subjects studied (i.e., 640 alleles), respectively, and no linkage between them was observed. The frequency of allelic combination between the two polymorphisms was $1.6 \%$ (5 among 320 subjects).

The G134A polymorphism was observed in 24 cancer patients (30\%). One homozygote was found among them. Of those 23 heterozygous carriers, 2 patients had both the G134A and G184C polymorphisms (designated $\mathrm{G} 134 \mathrm{~A} / \mathrm{G} 184 \mathrm{C}$ ). A slightly lower percentage of controls (26.3\%) carried the G134A polymorphism. This polymorphism was found in both alleles in 3 of the controls and was present in 1 copy for the remaining 60 individuals. Three control individuals carried both the G134A and G184C polymorphisms. The group of subjects without the G134A polymorphism was set as baseline $(O R=1.00)$. The OR for subjects with at least one G134A-containing allele was $1.23(95 \% \mathrm{Cl}$, 0.68 2.20; $P=0.49$ ). Statistical analyses demonstrated that there was no significant association between the G134A polymorphism and lung cancer risk.

In contrast, the $\mathrm{G} 184 \mathrm{C}$ polymorphism was detected in 5 cancer patients and 5 controls. None of the individuals in this study were homozygous for the G184C polymorphism. If the subjects lacking the G184C polymorphism were set at an $O R=1.00$, then the OR for lung cancer in subjects with the G184C polymorphism was $3.37(95 \% \mathrm{Cl}, 0.89 \sim 12.73 ; P=0.07)$. The data indicate that subjects with the $\mathrm{G} 184 \mathrm{C}$ polymorphism have a near-significantly increased risk of lung cancer.

To investigate whether any gene-environment interactions exist, the subjects were further divided according to their smoking status (Table 3). The OR for smokers containing one of these polymorphisms was calculated using non-smoker subjects lacking these polymorphisms as a baseline $(O R=1.00)$. The $\mathrm{G} 134 \mathrm{~A}$ polymorphism only slightly increased lung cancer risk among the subjects with a current or previous history of smoking. These smokers with at least one G134A-containing allele had an OR of $7.91(95 \% \mathrm{Cl}, 2.67 \sim 23.43 ; P<$ $0.01)$, whereas those lacking this polymorphism had an OR of 6.48 (95\% Cl, 2.48 16.92; $P<0.01)$.

In contrast, smokers with a G184C-containing allele had an OR of $24.72(95 \% \mathrm{Cl}, 4.48 \sim 136.31 ; P<0.01)$, whereas those smokers lacking this polymorphism had an OR of $6.65(95 \% \mathrm{Cl}, 2.72 \sim 16.28 ; P<0.01)$. This demonstrates an increased risk for the smokers with the G184C polymorphism in developing lung cancer.

In summary, our findings suggest that it is unlikely that the G134A polymorphism influences lung cancer risk. However, individuals with the G184C polymorphism, especially those with a history of smoking, have an increased risk of acquiring lung cancer. Additional studies will be required to evaluate the effects of these polymorphisms on the metabolism of xenobiotics and their roles in carcinogenesis.

\section{ACKNOWLEDGEMENTS}

This work was supported by Korea Research Foundation Grant KRF 2005-E00046.

\section{REFERENCES}

Bartsch, H., Nair, U., Risch, A., Rojas, M., Wikman, H. and Alexandrov, K. (2000). Genetic polymorphism of CYP genes, alone or in combination, as a risk modifier of tobacco-related cancers. Cancer Epidemiol. Biomarkers Prev., 9, 3-28.

Crofts, F., Cosma, G.N., Currie, D., Taioli, E., Toniolo, P. and Garte, S.J. (1993). A novel CYP1A1 gene polymorphism in African-Americans. Carcinogenesis., 14,1729-1731.

Cascorbi, I., Brockmoller, J. and Roots, IA. (1996). C4887A polymorphism in exon 7 of human CYP1A1: population frequency, mutation linkages, and impact on lung cancer 
susceptibility. Cancer Res., 56, 4965-4969.

Chevalier, D., Allorge, D., Lo-Guidice, J.M., Cauffiez, C., Lhermitte, M., Lafitte, J.J. and Broly, F. (2001). Detection of known and two novel (M331I and R464S) missense mutations in the human CYP1A1 gene in a French Caucasian population. Hum. Mutat., 17, 355.

Hayashi, S., Watanabe, J., Nakachi, K. and Kawajiri, K. (1991). Genetic linkage of lung cancer-associated Mspl polymorphisms with amino acid replacement in the heme binding region of the human cytochrome P450IA1 gene. J. Biochem., 110, 407-411.

Hung, R.J., Boffetta, P., Brockmoller, J., Butkiewicz, D., Cascorbi, I., Clapper, M.L., Garte, S., Haugen, A., Hivonen, A., Anttila, S., Kalina, I., Le Marchand, L., London, S.J., Rannug, A., Romkes, M., Salagovic, J., Schoket, B., Gaspari, L. and Taioli, E. (2003). CYP1A1 and GSTM1 genetic polymorphisms and lung cancer risk in Caucasian non-smokers: a pooled analysis. Carcinogenesis, 24, 875-882.

McManus, M.E., Burgess, W.M., Veronese, M.E., Huggett, A., Quattrochi, L.C. and Tukey, R.H. (1990). Metabolism of 2-acetylaminofluorene and benzo(a)pyrene and activation of food-derived heterocyclic amine mutagens by human cytochromes P-450. Cancer Res., 50, 3367-3376.

Park, D.W., Jin, B., Jang, D., Yang, K., Park, J.D., Lee, Y.S. and Ryu, D.Y. (2004). Genetic polymorphisms of CYP1A1 in a Korean population. Arch. Toxicol., 78, 306-308.

Spurr, N.K., Gough, A.C., Stevenson, K. and Wolf, C.R. (1987). Msp-1 polymorphism detected with a cDNA probe for the P-450 I family on chromosome 15. Nucleic Acids Res., 15, 5901

Smart, J. and Daly, A.K. (2000). Variation in induced CYP1A1 levels: relationship to CYP1A1, Ah receptor and GSTM1 polymorphisms. Pharmacogenetics, 10, 11-24.

Saito, S., lida, A., Sekine, A., Ogawa, C., Kawauchi, S., Higuchi, S., Ohno, M. and Nakamura, Y. (2002). 906 variations among 27 genes encoding cytochrome P450 (CYP) enzymes and aldehyde dehydrogenases (ALDHs) in the Japanese population. J. Hum. Genet., 47, 419-444.

Solus, J.F., Arietta, B.J., Harris, J.R., Sexton, D.P., Steward, J.Q., McMunn, C., Ihrie, P., Mehall, J.M., Edwards, T.L. and Dawson, E.P. (2004). Genetic variation in eleven phase I drug metabolism genes in an ethnically diverse population. Pharmacogenomics, 5, 895-931.

Song, N., Tan, W., Xing, D. and Lin, D. (2001). CYP 1 A1 polymorphism and risk of lung cancer in relation to tobacco smoking: a case-control study in China. Carcinogenesis, 22, 11-16.

Sugimura, H., Wakai, K., Genka, K., Nagura, K., Igarashi, H., Nagayama, K., Ohkawa, A., Baba, S., Morris, B.J., Tsugane, S., Ohno, Y., Gao, C., Li, Z., Takezaki, T., Tajima, K. and Iwamasa, T. (1998). Association of lle462Val (Exon 7) polymorphism of cytochrome P450 IA1 with lung cancer in the Asian population: further evidence from a case-control study in Okinawa. Cancer Epidemiol. Biomarkers Prev., 7, 413-417.

Vineis, P., Veglia, F., Benhamou, S., Butkiewicz, D., Cascorbi, I., Clapper, M.L., Dolzan, V., Haugen, A., Hivonen, A., Ingelman-Sundberg, M., Kihara, M., Kiyohara, C., Kremers, P., LeMarchand, L., Ohshima, S., Pastorelli, R., Rannug, A., Romkes, M., Schoket, B., Shields, P., Strange, R.C., Stucker, I., Sugimura, H., Garte, S., Gaspari, L. and Taioli, E. (2003). CYP1A1 T3801 C polymorphism and lung cancer: a pooled analysis of 2451 cases and 3358 controls. Int. J. Cancer, 104, 650-657. 